\title{
The disrupted basal ganglia and behavioural control: An integrative cross-domain perspective of spontaneous stereotypy
}

\author{
4 Q1 Sebastian D. McBride ${ }^{\mathrm{a}}$, Matthew O. Parker ${ }^{\mathrm{b}, *}$ \\ 5 Q2 a Department of Physiology, Development and Neuroscience, University of Cambridge, Cambridge, UK \\ b School of Biological and Chemical Sciences, Queen Mary University of London, London E1 4NS, UK
}

\section{H I G H L I G H T S}

- Spontaneous stereotypy is a behavioural manifestation of poor welfare.

- We present a new model of basal ganglia dysfunction in spontaneous stereotypy.

- Taking a cross-domain approach informs us about the potential neurophysiological basis of stereotypy.

\section{A R T I C L E I N F O}

\section{Article history:}

Received 19 February 2014

Received in revised form 16 May 2014

Accepted 26 May 2014

Available online xxx

\section{Keywords:}

Stereotypy

Basal ganglia

Striatum

Reciprocal feedback

Non-reciprocal feedback

Dopamine

Q4 Cross-domain

\begin{abstract}
A B S T R A C T
Spontaneous stereotypic behaviour (SB) is common in many captive animal species, as well as in humans with some severe psychiatric disorders, and is often cited as being related to general basal ganglia dysfunction. Despite this assertion, there is little in the literature examining SB specifically in terms of the basal ganglia mechanics. In this review, we attempt to fill this gap by offering an integrative, cross-domain perspective of SB by linking what we currently understand about the SB phenotype with the ever-growing literature on the anatomy and functionality of the basal ganglia. After outlining current models of SB from different theoretical perspectives, we offer a broad but detailed overview of normally functioning basal ganglia mechanics, and attempt to link this with current neurophysiological evidence related to spontaneous SB. Based on this we present an empirically derived theoretical framework, which proposes that SB is the result of a dysfunctional action selection system that may reflect dysregulation of excitatory (direct) and inhibitory (indirect and hyperdirect) pathways as well as alterations in mechanisms of behavioural switching. This approach also suggests behaviours that specifically become stereotypic may reflect inbuilt low selection threshold behavioural sequences associated with early development and the species-specific ethogram or, low threshold behavioural sequences that are the result of stress-induced dopamine exposure at the time of performance.
\end{abstract}

(C) 2014 Published by Elsevier B.V.

\section{Introduction}

Stereotyped or stereotypic behaviours (SB) have historically been described as repetitive, topographically invariant response sequences that appear to lack any ultimate or proximal function [1]. SB can be either psychostimulant-induced [2-5,5-12], environmentally-induced [13] [14-18] and are often associated with human developmental disorders (e.g. autism [19]), neurological disorders (obsessive compulsive disorder, OCD; Giles de la Tourette's syndrome; GTS; [20-22]) and severe psychiatric

* Corresponding author. Tel.: +4407986205349.

E-mail addresses: sdm47@cam.ac.uk (S.D. McBride), matthew.parker@qmul.ac.uk (M.O. Parker). disturbances (e.g. schizophrenia [23-25]). Non-human SBs include locomotor ('pacing' or 'route tracing') and oral ('sham chewing', 'bar mouthing' and 'cribbing') behaviour patterns (see [18]). Human SBs include minor repetitive motor actions, such as tics, full body SB such as 'rocking', or ritualised sequences of complex behaviours [26-30]. Whether non-human or human, SBs share the characteristics of being ritualised, habitual and often compulsive (in the sense that their performance often overshadows all competing behaviours) [21]. The three categories of SB (psychostimulant, spontaneous, human developmental/neuropsychiatric) although qualitatively quite different, may contain substantial morphological and neurophysiological overlap. Our main focus in this review is to present our thesis on environmentally-induced (spontaneous) SB in particular. However, in the interests of offering a crossdomain perspective, we will integrate discussion of translationally 
relevant comparative data from pharmacologically induced and neuropsychiatric models of SB.

Research to date identifies spontaneous animal SB as a multifaceted construct that has a substantial genetic component, is strongly predicted by assumed "chronic stress" associated with environmental restriction of species-typical behaviour (e.g. the more at variance the housing environment of captive animals is from their naturally free-ranging environment, the more likely they are to show SB), and is the result of altered basal ganglia physiology (see $[31,32]$ for recent reviews). This account, however, cannot provide a convincing explanation of how and why a shift in neurophysiological function within the basal ganglia results in the development and manifestation of repetitive sequences of behaviour. The purpose of this review, therefore, is to consider:

(1) What are the key defining causal and neurophysiological characteristics of the spontaneous SB animal phenotype?

(2) What do we currently know about normal basal ganglia mechanics in producing behavioural control and what does the psychostimulant-induced SB literature tell us about how alteration of normal basal ganglia mechanics could lead to repeated sequences of behaviour (SB)?

(3) How does information from (Q2) inform us about the neurophysiological characteristics of the spontaneous SB phenotype?

In this review we will draw on studies and theories from ethology, neurology, psychology, pharmacology and neurobiology. The cross-domain integration of translationally relevant facets of these often-conflicting theoretical perspectives will expedite the development of biologically relevant causal models of spontaneous SB. For example, while psychology may inform us about general animal well-being, and neurology about potential differences in behavioural function, a clear understanding of the fine-motor control mechanisms that may be involved with complex SBs may come from pharmacologically-induced models. As such, by adopting a cross-domain approach, we hope to offer a very detailed insight into many aspects of SB, but also further insight into normal and disrupted basal ganglia functioning.

\section{What are the key defining causal and neurophysiological characteristics of the spontaneous SB animal phenotype?}

In the first section of this review, we describe the putative causal factors and general environmental conditions that are proposed to constitute risk factors for SB development. As part of the cross-domain approach, we will discuss ethological models of behavioural motivation and give an overview of some human models of SB to further deconstruct the role of risk factors in eliciting SB, but also to provide a mechanistic framework upon which neurophysiological evidence can be critically analysed.

\subsection{Stress as a mediator of SB: Beyond the 'coping' hypothesis}

Spontaneous SBs rarely occur in feral or semi-feral populations of animals, suggesting that their development is an artefact of the captive or domestic environment [33-35]. Restricted or sub-optimal housing conditions, particularly involving marked incongruity from the species' feral environment, represent a significant risk factor in the development of SB (e.g. [35-37]). Thus, spontaneous SB in captive animals is associated with stress and often perceived as an indicator of existing or previous poor welfare, and has previously been described as a 'coping mechanism' in this context $[1,33]$.

In its most general form, stress refers to the physiological response to a psychological or physical 'stressor' [38]. In other words, stress can be operationally defined as any event or perception that leads to a physiological stress response. Although 'stress' is frequently referred to when describing the aetiology of spontaneous SB [1,39-42], there are limitations in using this term. First it is a complex and heterogeneous construct [43] and as a result there is variation in how it is interpreted [44]. Second, stressors differ both qualitatively (psychological or physical) and quantitatively (e.g. chronic, acute, chronic intermittent) [45-47], and different individuals respond (physiologically and behaviourally) to the same stressors in quite disparate ways $[47,48]$. As a consequence, not all stressors will cause SB, and some stressors will be significant risk factors for SB in some species, but not in others. For example, although food restriction, social isolation and restricted locomotion have all been linked to SB development, cold, immobilisation and inescapable electric shock have not (see [49] for review). In addition, not all individuals that share the same environment develop SB [50,51], whereby stress and propensity for SB development is highly influenced by genotype [52-54]. Cabib et al. [55,56], for example, reported a significant genotype-dependent effect of different stressors on SB development in mice that was mediated through DAergic activity (to be discussed in Section 3).

Although stress may be considered too ambiguous a term, specific stressors have been consistently linked to the development of SB in several species. For example, restricted food intake reliably causes stereotypic pecking in poultry [57-59], whilst for pigs, this together with restriction of locomotion causes stereotypic headweaving, chain manipulation, bar-biting and sham chewing $[50,60]$ Prevention of locomotion causes stereotypic jumping by bank voles [61], whilst in similar conditions mink perform stereotypic pacing and rearing [48]. Also in mink, feed-restriction is reported to have a similar effect [62]. Cows tongue-roll when food is restricted $[63,64]$ or when they are confined [65], restricted feeding or social isolation induces SB in sheep [66] and social isolation has the same effect in dogs [67].

To summarise, while there is significant overlap between the effects of different stressors on the risk to develop SB, there is certainly much variation at both a species and stressor level with genotypic predisposition playing an important role.

\subsection{An ethological framework for SB development}

Ethological models of behavioural motivation have been used to determine the relationship between internal and external stimuli in eliciting and terminating behaviours [68]. Such models are therefore important in understanding the causal and functional aspects of SBs since they are characterised by non-termination of behaviour sequences. Here we revisit some of these models in the context of SB as a platform for critical analysis within the neurophysiological domain.

Many of the motivation models originate from Lorenz's psychohydraulic model [69] (water pressure symbolising motivation within a threshold-based system) and von Holst's Sollwert-Istwert model [70] (discrepancy between perceived states [current and desired] determining and directing motivation). These models suggest that for continual repetition of a behavioural sequence to exist, the respective level of motivation must (a) always be above threshold and (b) perpetually outcompete other prospective behavioural sequences. Conversely, SBs rarely constitute $100 \%$ of the time budget and thus, within this framework, motivational levels of SBs must vary sufficiently for other competing behaviours to emerge.

One of the most pertinent models of motivation in respect to SB is that that proposed by Hughes and Duncan [71]. This model was aimed primarily at explaining the concept of animal 'behavioural needs' but also to explain the motivational basis of SBs. The model is based on the premise that goal-directed behaviours have two distinct components, anticipatory/appetitive and 


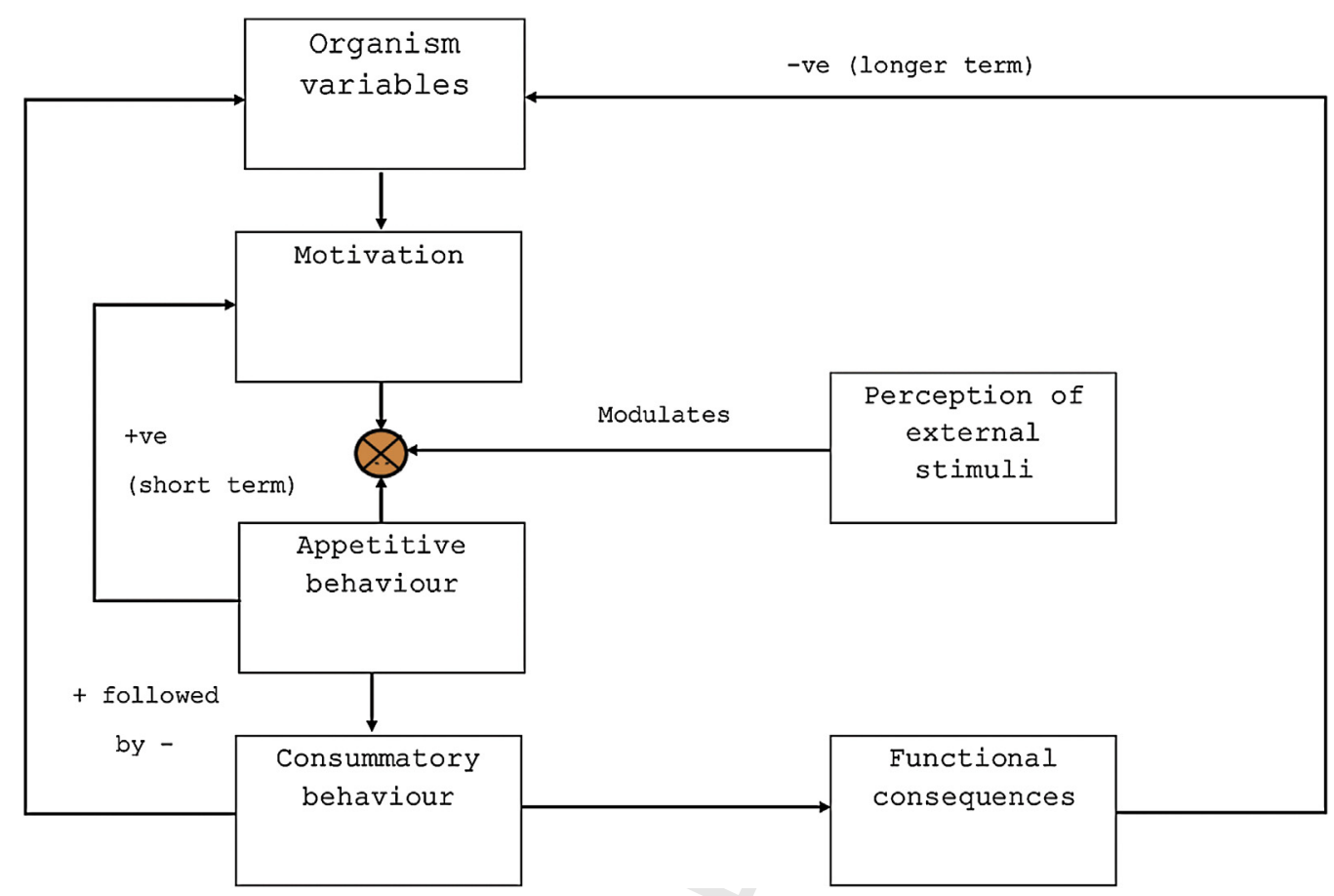

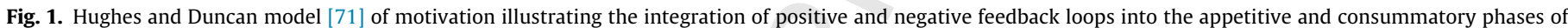
goal-directed behaviour.

terminal/consummatory (Fig. 1). Depending on the state of internal 'organism variables' (e.g. blood glucose levels), motivation to perform a goal-orientated consummatory behaviour (e.g. feeding) can result. Consequently, appetitive behaviour takes place (e.g. locomotory action to access food), followed by the consummatory act. The appetitive behaviour has a short-term positive feedback on motivation and is thus self-reinforcing. The act of consummation has a number of effects; (1) functional consequence (e.g. elevated blood glucose), which leads to negative feedback on organism variables with a subsequent effect on motivation, (2) direct feedback on motivation, initially positive and then negative, and (3) an effect on perception of the animals environment which again influences the underlying motivation of the behaviour. Hughes and Duncan argued that SBs are appetitive in origin because the restrictive nature of the animal's environments prevents consummatory behaviours from being performed. Lack of consummation and subsequent functional consequence means that no negative feedback on motivation takes place. Appetitive behaviours thus continue because of the lack of negative feedback but also because internal/external cues of the behaviour persist. This results in the animal getting locked in a positive feedback loop and repetition of the same behavioural sequence. Thus for example, post-prandial SBs are the result of continued eating motivation arising from restriction of food supply; the lack of negative feedback sustains the motivation to eat resulting in the continued performance of an appetitive behaviour [15,72]. Similarly, pre-prandial SBs, in response to external (conditioned) stimuli that signal food arrival, develop and persist as a result of a confined environment which prevents and, thus, sustains the motivation to perform locomotory action to gain food. This model suggests a linear positive correlation between the level of motivation to perform the unobtainable goal and the likelihood of remaining in the appetitive loop and thus SB development.

SBs are, however, not always performed in the context of explicit external and internal stimuli such as food arrival or feeding to produce (to induce pre- and post-prandial SB). These between-meal or 'facultative' [72] SBs are more difficult to explain in terms of the Hughes and Duncan model because restriction of consummatory behaviours and subsequent lack of negative feedback is less apparent. It may be, however, that these behaviours arise from the continued motivation to perform non-feeding consummatory or associated appetitive behaviours e.g. social or sexual behaviour. However, these SBs often appear to be a response to a lack of environmental stimuli, (for review see [1]). This led to the suggestion that $\mathrm{SB}$, in this context, may have a functional capacity in allowing the animal to 'cope' with its environment (for review see $[1,18]$ ).

In conclusion, certain ethological models of motivation suggest that SB originate from:

(1) one behavioural sequence predominating within a threshold selection system such that it repeatedly monopolises the action selection process with high motivation maintained through continued presentation of external/internal cues;

(2) a lack of inhibitory feedback mechanism (in relation to attaining the consummatory goal) to prevent the replay of the behaviour sequence.

In addition, the inability of the Hughes and Duncan model to explain non-cued SB can be interpreted as SB itself being selfreinforcing which would lead to it dominating the action selection process (see Section 2.3 for further discussion of this).

\subsection{Human repetitive disorders as a model for animal $S B$}

Human SB are a diagnostic feature of a number of psychiatric, developmental and neurological disorders such as autism, obsessive compulsive disorder (OCD) and Gilles de la Tourettes syndrome (GTS) [73,74]. SB in individuals with autism is considered as clinically 'problematic': (1) SB can be socially stigmatising for the individual, and (2) because SB tends to occupy large percentages of the overall time budget, it can interfere with normal learning [75]. This has spurned interest from clinical researchers attempting to understand the causal basis of SB. In autism, SB can be described as translationally relevant to those observed in 
captive animals according to some authors. For example, the social and environmental deprivation that act as risk factors for spontaneous SB are conceptually similar to those observed in autism (deficits in social interaction) Bodfish, Symons [73]. Early research into SB in autism characterised the behaviour as an operant, under the control either of positive or negative reinforcement contingencies. Lovaas and colleagues [76] described SB in terms of 'self-stimulatory' behaviours, shaped and maintained by automatic reinforcement (sensory feedback). The performance of the behaviour may be controlled by stimuli from any perceptual domain under this hypothesis. Support comes from a variety of sources; for example, in the case of autism, SBs are often very complex behavioural rituals suggesting that some degree of shaping must have occurred (i.e. the behaviours are unlikely to be innate and spontaneous). This theory, however, has been severely criticised on the grounds of it being effectively unfalsifyable, with a lack of operational definitions of what constitutes perceptual reinforcement available. Some attempts have been made to further characterise SB in operational terms. These have typically characterised the reinforcing stimuli as being exeroceptive, such as social positive reinforcement (praise), social negative reinforcement (task avoidance) or other tangible forms of positive (food) or negative (avoidance of environmental stimuli) reinforcement (see [77] for review). The characterisation of spontaneous animal SB in these terms, however, is not helpful in determining the underlying causes of the behaviour. In particular, it does not address why (a) only a (relatively) small proportion of animals engage in the behaviour? (b) The behaviour is more common in certain environments than others (e.g. impoverished environments) and c) why these behaviours take on idiosyncratic species-typical patterns (e.g. crib biting in horses)?

Animal SB may also be conceptualised in terms of the aetiology and underpinning neurology of human repetitive disorders. For example, identified risk factors for GTS in humans share many similarities with those proposed for spontaneous animal SB; genetic predisposition, acute or chronic (social) stress, extreme emotional excitement and exposure to stimulant drugs have all been cited as risk factors for both GTS [22] and spontaneous SB [78]. Research has shown a high co-morbidity and cross-over of neurophysiological changes between OCD and stress-related disorders such as posttraumatic stress disorder (PTSD) [79]. Evidence also suggests that psychosocial stress in particular predicts the severity of symptoms in OCD and GTS [80,81]. Experiencing early stressful events (e.g. foetal distress) represent a risk factor for GTS [81], and there is an increase in the symptoms of GTS following thermal stress (controlled exposure to heat) [82]. A comprehensive study on the effects of different environmental events on symptoms of GTS showed that certain types of psychosocial stress (e.g. social anxiety) were important risk factors, as were extreme fatigue or trauma. Other psychosocial factors, however, (e.g. being socially isolated) were not found to be risk factors [83]. Children with GTS show higher levels of noradrenaline and adrenocorticotrophic hormone (ACTH) preceding a lumbar puncture [84]. Also, anti-anxiety drugs such as fluoxetine have been shown to have a beneficial effect on some of the compulsive symptoms of OCD as compared to placebo [85].

Given the overlap in aetiology and morphology of human and animal SB, research on the neurological basis of the former may be well provide additional insight into the latter and will therefore be discussed in the following neurophysiological sections.

\subsection{Neurophysiological characteristics of $S B$}

Table 1 displays the current evidence relating to the neurophysiological correlates of SB. Observations of the capacity for psychostimulants to induce SB steered the direction of neurophysiological research underpinning spontaneous SB towards DAergic systems within the basal ganglia nuclei. Pioneering work by Randrup and Munkvad [86] induced SB through systemic amphetamine administration in a range of species (including humans). This work continued to be extensively and reliably replicated (for reviews see $[49,87]$ ) identifying DA as the pertinent neurotransmitter underpinning psychostimulant-induced SB. For example, microinjection of the dopamine D1 receptor (DRD1) agonist A68930 into the striatum induced contralateral rotation SB to the side of the injection [88] and bilateral striatal infusion of the DRD1 antagonist SCH23390 produced a dose-dependent reduction in levels of spontaneous stereotypic jumping in mice without inhibiting nonstereotypic motor behaviour [89]. Furthermore, lesioning DAergic transmission of the dorsal striatum in rats, whilst keeping intact the ventral striatum, prevented motor SB induction through DA agonists, while lesioning DAergic transmission of the ventral striatum resulted in decreased locomotor activity after the same psychostimulants were administration [90].

These and other similar observations led to the hypothesis that systemic administration of DA antagonists would attenuate spontaneous SBs. This hypothesis was supported in a range of species, primarily using the dopamine D2 receptor (DRD2) antagonist haloperidol, including bank voles [91], chickens [92], pigs [93] and cats [94], but was not always successful (see [95]). Many additional studies [96-98] reported a similar effect of administering opioid antagonists, primarily due to the ability of these compounds to modulate DAergic tone within the basal ganglia system [99]. Other work has demonstrated a significant reduction of spontaneous SB performance on intrastriatal administration of glutamate (NMDA) [89] and systemic administration of adenosine A1 and A2a receptor agonists in deer-mice [100]. Although collectively these data suggest significant overlap in the neurophysiological mechanisms underpinning both pharmacologically- and environmentally-induced SB, other studies have suggested that this may in fact not be the case. For example, SB performance in deermice was not exacerbated through intrastriatal administration of either DRD1, DRD2 or DRD1/DRD2 receptor-specific DA agonists. This more detailed analysis suggests that the two forms of SB may not share the same neural substrates [95].

More recent work has assessed the neurophysiological differences within the basal ganglia between normal and SB phenotypes. For example, SB mice have a significant up-regulation of DRD1 and DRD2 in the ventral striatum with concurrent down-regulation of DRD2 autoreceptors in the ventral tegmentum area of the mid-brain [56,101-103]. Similar observations have been made in the horse, where stereotypic (crib-biting) animals had significantly higher DRD1 and DRD2 subtypes in the ventral striatum and significantly lower DRD1 in the dorsomedial striatum compared to controls [104]. Presti and Lewis [105], reported high dynorphin/enkephalin ratios in the dorsolateral striatum of high, compared to low, spontaneous SB deer mice and Tanimura and colleagues [100] observed significantly reduced activation of the subthalamic nucleus (STN) in high spontaneous SB deer mice that was reinstated through systemic administration of adenosine agonists.

Indirect behavioural measures of altered basal ganglia function have also started to emerge in relation to the SB phenotype. Garner et al. [13] performed a battery of tests on stereotypic caged songbirds involving standard extinction paradigms and sequential responding in a gambling task. They reported that SB levels were remarkably strong predictors for the latency to extinguish conditioned responses (CRs) in the extinction procedures and 'predictable' response patterns (i.e. as opposed to maximizing income) on the gambling task. These findings were interpreted as evidence for a direct relationship between SB and physiological shifts in the striatum and/or prefrontal-striatal regulation. The extinction findings have been extended to include 
Table 1

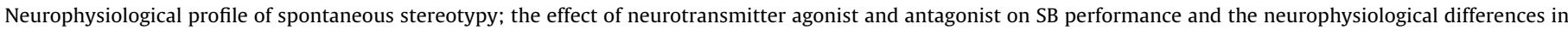

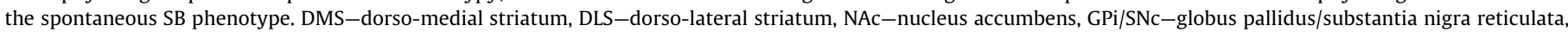
GPe-globus pallidus externus, STN-subthalamic nucleus. $\uparrow$ increase, $\downarrow$ decrease, - no effect.



The effect of DA agonist on existing spontaneous stereotypy.

non-laboratory species including horses [106], bears [107], mink [108] and rhesus macaques [109] (although also see [110]). Other behavioural correlates have also been seen, for example in stereotypic horses. For example, crib-biting horses showed insensitivity to delay in an instrumental choice procedure [111] which was considered a marker for dorso-medial striatum dysregulation. SB horses were also shown to have a greater propensity for stimulus-response ( $\mathrm{S}-\mathrm{R}$ ) as opposed to response-outcome $(\mathrm{R}-\mathrm{O})$ learning. This difference in learning strategy was interpreted as accelerated dorso-lateral shift of cortico-striatal loops potentially as a result of dysregulated dorso-medial striatum [112]. Finally, a direct correlation between SB performance and the number of errors during reversal learning was observed in mice, interpreted as dysregulation of cortico-basal ganglia circuitry [113].

In relation to human repertive disorders, dopamine antagonists are often prescribed to patients with these conditions [22]. Similarly, dopamine transporter (DAT) knockdown mice are used as a model of both GTS and OCD owing to their high levels of SB. In OCD, a potential neural circuit has been identified that is similar to that which has been characterised in substance abuse: specifically, the anterior cingulate and orbito-frontal cortices and their projections to thalamic nuclei and to the ventral and dorsal aspects of the striatum [20,21,114]. Finally, patients with GTS have different degrees of cortical thinning which negatively correlates with tic severity in a variety of regions [115]. For example, simple tics were associated with thinning in the primary motor regions, but more complex tics were associated with thinning across premotor, prefrontal and parietal cortex. Interestingly, patients with comorbid OCD symptoms also show thinning in the anterior cingulate cortex, a region linked to compulsive substance abuse and other forms of dysfunctional habit formation [116].

In summary (see Table 1), evidence suggests that the basal ganglia are key structures in the mediation of spontaneous SB. Indirect behavioural measures also suggest that the prefrontal cortex-basal ganglia complex may be equally as important. Although there is substantial evidence that dysregulated DAergic modulation of the basal ganglia is the primary mechanism by which SB manifest, other evidence suggests that the mechanism may in fact be much more complex involving the inter-relationship of DA with glutamate and adenosine. The following section outlines the primary functional mechanics of the basal ganglia, as it currently stands, to allow closer scrutiny of the neurophysiological profile of spontaneous SB.

\section{How does normal basal ganglia function produce behavioural control?}

In the previous section, we discussed current neurobiological models of SB. These models are based on pharmacological manipulations of SB and non-SB animals and indirect behavioural observations. While these models are heuristically very useful, they certainly do not provide a full account of SB. Consideration of the functional role of the basal ganglia may help to provide the basis of a more complete understanding of the basis of SB, and in this section, we will attempt to outline the primary and currently accepted normal structure and function of this brain region.

\subsection{Neuroanatomical and physiological attributes of the basal ganglia}

\subsubsection{Primary structures and the direct, indirect and hyperdirect pathway}

Fig. 1 illustrates the main structures of the basal ganglia. The basal ganglia primarily comprises the striatum, the subthalamic nucleus (STN), globus pallidus (GP; internal: GPi; external: GPe), substantia nigra (SN; pars compacta: $\mathrm{SNc}$; pars reticula: $\mathrm{SNr}$ ) and ventral tegmental area (VTA). The largest structure, the striatum, forms the main neural gateway to the basal ganglia. It comprises the caudate, located dorsomedially (DMS), the putamen, located dorsolaterally (DLS), and the nucleus accumbens (NAc), located within the ventral aspect. The NAc can be further separated functionally and anatomically into the shell (NAcs) and core (NAcc) region. For the majority of species, $95 \%$ of the striatum is made up of medium-spiny (MSNs) projection neurons and 5\% interneurons (cholinergic and GABAergic) [117]. Striatal afferents project primarily from the cortex, hippocampus, thalamus, amygdala, dorsal raphe nucleus, STN and from different mid-brain structures (SNc and VTA) $[118,119]$. With regard to the cortex, there is a generalised but graded arrangement of cognitive control and reward areas (e.g. prefrontal cortex) sending projection neurons to the ventral striatum (NAC and ventral caudate), association areas (e.g. parietal cortex) innervating dorso-medial striatum and finally motor areas (e.g. motor cortex) innervating dorsolateral striatum [118,120] (Fig. 2).

Striatal MSNs have extensively arborised dendritic trees and receive widespread cortical, medullary and limbic input. This morphological arrangement of 'many to one' is one of the key characteristics of MSNs and creates a system whereby only specific 

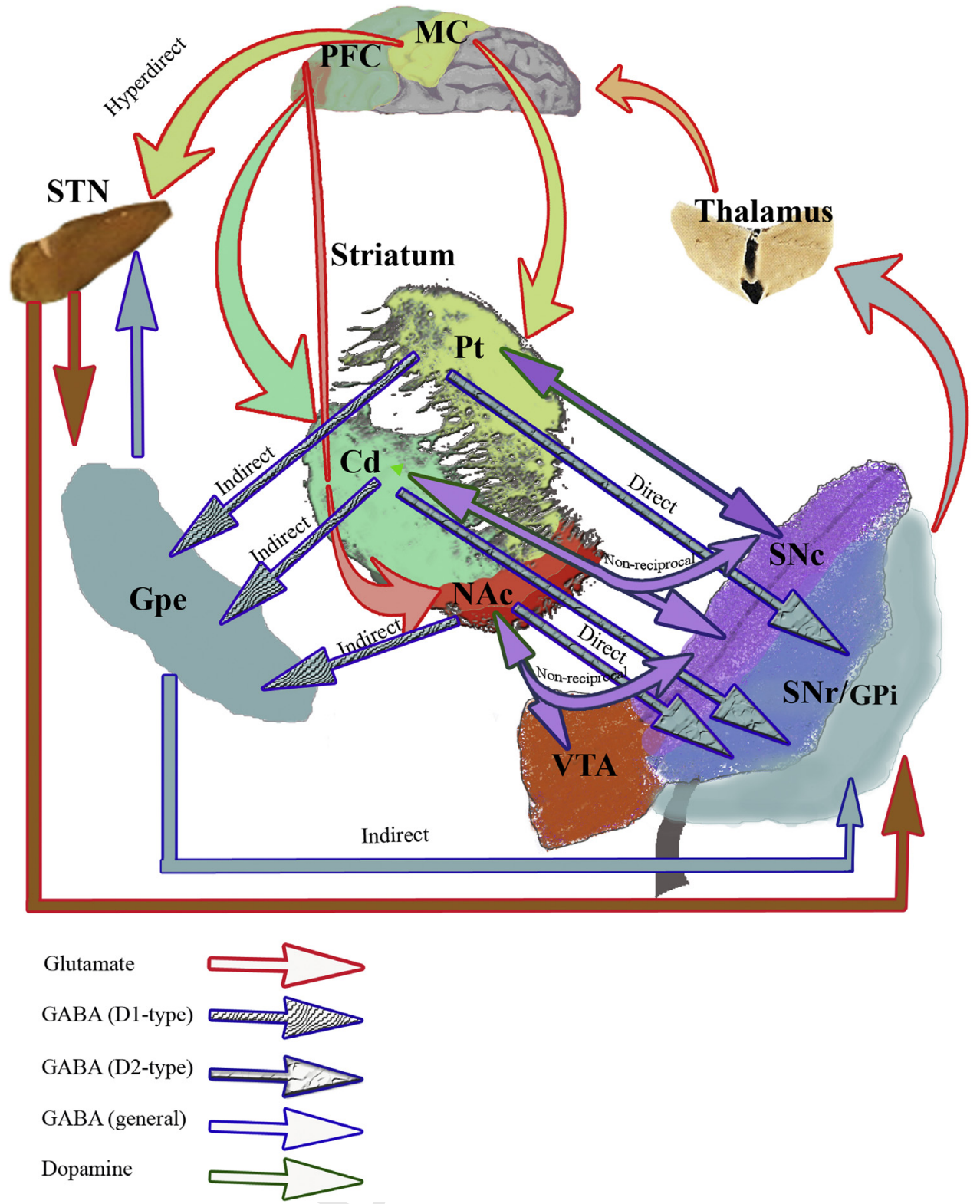

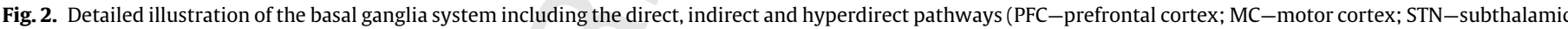

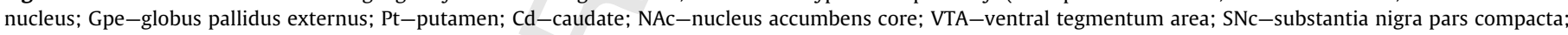
$\mathrm{SNr}-$ substantia nigra pars reticulate; $\mathrm{GPi}-$ globus pallidus internus).

combinations of dendritic activity, which originate from a wide range of cortical and sub-cortical structures, may elicit an MSN action potential $[121,122]$. It is generally considered that cortical information is transferred via the basal ganglia to the thalamus and back to the cortex through three different pathways; the direct and indirect pathway through the striatum and the hyperdirect pathway through the STN [123-125] (Fig. 2). The direct pathway consists of a direct inhibitory GABAergic projection from the striatum to the $\mathrm{SNr} / \mathrm{GPi}$ which also projects GABAergic neurons onto the thalamus. This double inhibitory system means that cortical input into the striatum has the potential to disinhibit the thalamus allowing a return of information back to the cortex [124]. The indirect pathway involves inhibitory GABAergic projection from the striatum to the GPe which then projects inhibitory GABAergic neurons onto both the SNr/GPi and STN. The inhibitory neurons onto $\mathrm{SNr}$ /GPi form a triple inhibition system such that cortical initiation of the indirect pathway results in increased inhibition of the thalamic output and thus attenuated return of cortical information. The STN has historically been included as part of the indirect pathway but is now discussed as the hyperdirect pathway [126]. Primary STN efferents are glutamatergic and thus excitatory, targeting both pallidal structures of the direct and indirect pathway (SNr/Gpi and GPe, respectively) [127]. Theoretically therefore the STN has the opportunity to increase activation of the both the direct and indirect pathway but highly is also modulated by the GABAergic feedback loop from GPe back to STN [127]. This complex relationship of the STN in modulating and being modulated by other basal ganglia structures results in a signature triphasic response of the $\mathrm{SNr}$ (the primary output structure to the thalamus); firstly early excitation as a result of hyperdirect pathway activation via the STN, secondly inhibition as a result of the GABAergic direct pathway activation, and finally late excitation as a result of the activation of the indirect pathway $[123,128,129]$. 


\subsubsection{A fourth pathway based on compartmentalisation of the striatum: Striosomes and matrix}

One other possible efferent pathway through the striatum originates from compartments within the striatum known as striosomes and the surrounding matrix. These differ in their spatial distribution, afferent and efferent projections as well as in their immunoreactivity [130-134]. Striosomes are distributed in a patchy manner across the dorsal striatum, express $\mu$ opioid-receptors, contain leu-enkephalin and substance $P$ and are calbindin poor $[99,135,136]$. Both compartments contain direct and indirect pathway MSNs, but MSNs within the striosomes also have direct projections to the SNc which contain DAergic neurons that project back to the dorsal striatum (discussed in the next section). Striosomes largely receive their input from limbic cortical structures such as the orbitofrontal and medial prefrontal cortex [130]. Thus a fourth basal ganglia pathway from the limbic cortical structures to the dorsal striatum via striatal striosomes and the SNc also exists.

\subsubsection{DAergic modulation of basal ganglia via mid-brain structures (SNC and VTA)}

DA is integral to striatal synaptic activity, with striatal excitatory post-synaptic potentials (EPSPs) largely modulated by mid-brain DA innervation $[137,138]$. The effect of DA differs, however, dependent on the type of MSN. For MSNs that express DRD1, muscarinic M4 receptors, dynorphin ( $\kappa$-opioid receptor) and substance P, DA has an excitatory effect, stimulating the direct pathway [139]. For MSNs that contain DRD2 and adenosine A2a receptors, and express enkephalin (delta opioid receptor), DA has an inhibitory effect, stimulating the indirect pathway [139]. DA neurons from the SNc and VTA directly target different striatal structures with the SNc modulating MSNs within the dorsal striatum (caudate and putamen) where the VTA corresponds to the ventral striatum (nucleus accumbens) [140]. DA modulation is not limited to the striatum with the globus pallidus, $\mathrm{SNr}$ and STN experiencing direct modulation from mid-brain structures via DAergic neurons (Perier et al., 2000 and Hassani and Feger, 1999). The functional importance of this additional DAergic modulation is still not fully understood.

\subsubsection{Reciprocal and non-reciprocal loops from the striatum to mid-brain structures}

A major feature of striatal mid-brain connectivity is the reciprocal feedback and non-reciprocal feed-forward mechanism. These allow regions of the striatum to modulate their own DA afferents (reciprocal feedback) but also to affect mid-brain DA modulation of other regions of the striatum (non-reciprocal feed-forward) [141]. This arrangement is such that DA innervation of the NAcs, as well as resulting in feedback to this same region, also has a feed-forward effect on the NAcc. What is critical here is that feedback is direct, causing inhibition, but feed-forward is indirect acting through a GABA inter-neuron and thus has an excitatory effect. In a similar fashion, NAcc feed-forward stimulates the DMS, and the DMS likewise the DLS [141].

\subsubsection{Interneurons of the striatum (GABAergic and cholinergic)}

The striatum also contains four classes of interneurons, cholinergic, GABA fast spiking (FS) and two types of GABA low-threshold spiking (LTS) interneurons, all of which have a complex modulatory function on striatal ouput [139]. Cholinergic interneurons, for example, either activate or deactivate the inhibitory effects of GABA interneurons (as a result of exposure to MSN secretions of substance $P$ and enkephalin) thus affecting overall striatal output [142]. Cholinergic interneurons also have a typical 'burst-pause' firing pattern whereby the burst element (induced by thalamic activation) results in presynaptic cortical inhibition via M2 muscarinic receptors on both direct and indirect pathway MSNs [143].
During the pause phase of cholinergic interneuron activation, there is also M1 muscarinic receptor-mediated postsynaptic facilitation of dendritic responsiveness in indirect pathway MSNs [143].

\subsection{Functionality of the basal ganglia from an action selection and $S B$ perspective}

The primary functionality of the basal ganglia is to allow animals to learn about outcomes associated with objects, events and situations (associative learning) within a variable environment and to select the most appropriate motor response (action selection) to promote survival $[144,145]$. They also collectively provide a mechanism for reduced computational load when outcomes of actions no longer need to be assessed through habit formation [146] as well as determining the motivation of goal-directed action [147]. The basal ganglia system is also involved in fine and gross motor control [148]. In the following sections, we will critically assess the mechanics of action selection within the basal ganglia in the context of the first two possible mechanisms of SB development.

\subsubsection{Learning and gating behavioural sequences-the basis of action selection}

Action selection is heavily biased by the learnt association between previous actions and appetitive or aversive events. Through this process of associative learning, objects, environments and events (cues) become predictive of other (biologically relevant) stimuli (positive or negative) and linked to specific behavioural sequences that will result in their presentation or removal (instrumental conditioning) [149]. Once learnt, subsequent presentation of these cues grabs attention and elicits motivation towards appetitive/evasive behaviours to re-attain the same goal. Often different cues of different predictive value occur concurrently, requiring the animal to execute the most appropriate action (action selection). The outcome of this decision in the normal functioning animal is directly affected by the motivation associated with each action, which, in turn, is determined by the perceived outcome resulting from its performance (or non-performance). In the following section we will discuss the possible mechanics of this system from a functional perspective in the light of the previous discussion on basal ganglia circuitry.

3.2.1.1. Learning: DA and long-term potentiation (LTP) and long-term depression (LTD). Using in vitro techniques, one of the most fundamental attributes of the basal ganglia appears to be synaptic strengthening (long-term potentiation [LTP]) and synaptic weakening (long-term depression [LTD]) (e.g. [150] mediated through the release of DA. This affords the basal ganglia, given its central position within the CNS, the powerful ability either to strengthen or to weaken connections between different brain regions. In the context of learning, excitatory cortical neurons containing both sensory information about the environment and cortical motor efferent copy-information (the continual log of what actions the animal has been performing) terminate at striatal MSNs [151-153]. If the action leads, for example, to presentation of an appetitively valenced stimulus, then learning the association between the action and the environmental context requires that a link is made between these two pieces of afferent information into the striatum. This process is potentially achieved through LTP as a result of DRD1 activation on the spine-shafts of MSN dendrites via the release of DA from the mid-brain (VTA, SNc) neurons [154,155]. Conversely, if the sensory information no longer predicts the arrival of salient stimuli, then the reverse process of LTD diminishes the link with the associated output $[155,156]$. What is not currently understood, however, is how linking afferent sensory and motor information at the point of the striatum during learning acquisition subsequently progresses to afferent sensory information being 
used to elicit appropriate motor action. One possibility is that concurrent activation of phasic DA at the time of cortical sensory input to the striatum allows the latter to traverse the basal ganglia in order to elicit a previously linked (learnt) motor action.

3.2.1.2. Gating an action selection. As outlined in Section 2, one of the main hodological divisions of the basal ganglia is the direct, indirect and hyperdirect pathways. This arrangement appears to be critically important for allowing information to pass through the basal ganglia (gating) and the basis for the action selection process [157-159]. The model by Gurney et al. [157] relies on the concept of actions acting as competing channels (originating from cortical glutamatergic projections to the striatum) whereby the direct pathway (through the double inhibitory GABA activity) augments the incoming channel with the highest activity, and the indirect pathway (via activation of the STN) augments and reduces the output of the most and least active competing channels, respectively [157]. Within this model, the tonic DA value acts as both as an excitatory (DRD1, direct pathway) and inhibitory (DRD2, indirect pathway) modulator of channel activity and that inhibition of the indirect pathway, via DRD2 activation, has an overall excitatory effect of basal ganglia output for that channel [157]. Thus, for a cortical signal to be gated through the basal ganglia, both the direct and indirect pathway are activated and inhibited, respectively, through DA release. This encapsulates the idea of the indirect pathway acting as a 'breaking' or 'control' mechanism over the direct pathway that needs to be released concurrently in order for the direct pathway to fulfil its gating function. This model of action selection is supported by DA agonist data that has demonstrated that co-binding to MSNs of both the direct and indirect pathways is a pre-requisite for behavioural output $[95,160,161]$, and more recent optogenetic work that has shown sustained D1 (direct) and inhibited D2 (indirect) MSN activity during learnt behavioural sequences [162]. However, the action selection process may also be more complex than this. Recent electrophysiological evidence has suggested that the indirect pathway is also active in some MSNs during action selection as a way of suppressing other non-selected behavioural sequences [163]. Thus, inactivation of the indirect pathway may be functionally responsible for facilitating an action selected by the direct pathway but conversely, concurrent activation may also be required in order to inhibit other actions competing with that selected by the direct pathway.

The hyperdirect pathway has been computationally modelled as a global break on basal ganglia output [158]. Here, the excitatory STN to SNr/GPi pathway predominates over the STN to GPe pathway, such that STN activation increases the inhibitory control of the SNr/GPi over the thalamus (and thus basal ganglia output) (Fig. 2). This has been interpreted functionally as a 'stall' or stop of behavioural output during high level conflict during the action selection process [164]. This model is supported by experiments that have directly correlated activity in the inferior frontal gyrus, the pre-supplementary motor area (pre-SMA) and the STN during reactive stopping paradigms $[159,165,166]$. Other experiments in rodents have demonstrated an increased number of premature responses in the 5-choice serial reaction time task (5-CSRTT) [167] and commission (sustained attentional) errors in a modified version of the stop signal task after an excitotoxic STN lesion $[168,169]$. Finally, deep implant electrodes have recently revealed significant correlations between cortical-STN coherence in different frequency bands associated with inhibition preparation, inhibition and motor initiation in human patients [170].

3.2.1.3. Action selection as the basis for behavioural switching. With action selection comes the ability to switch behaviours. Recent work has suggested that thalamic innervation of cholinergic interneurons (as described in Section 3.1.4) may be the means for this fast switching of behaviours to occur through a 'burst' mediated blocking of both MSN DRD1 and DRD2s followed by the facilitation of MSN DRD2s [143]. Switching is generally discussed in terms of incoming highly salient (i.e. attention-grabbing) stimuli that require an immediate override of ongoing behaviour; however, it may also be intrinsic to a more general process of terminating behavioural sequences once goals have been achieved. This raises the more general question of whether behavioural sequences, as discrete sets of goal-directed behaviour, require a stop signal or whether they are simply surpassed by other higher priority behaviours. Some recent work suggests that firing of midbrain DAergic projections to the dorsal striatum also temporally correlate with the termination of behavioural sequences and thus may constitute such a 'stop' signal [171]. Further research needs to be carried out to elucidate the functional importance of these findings. Understanding this mechanism may be extremely relevant to the discussion of SB, especially if they are interpreted as behavioural sequences without stop signals.

3.2.1.4. The NAC mediates motivation and behavioural vigour. As well as nigrostriatal activation, unconditioned stimuli and conditioned stimuli cause similar phasic activation of the mesoaccumbens (VTA-NAc) DA pathway [172]. The functional role of this phasic DA exposure of NAc MSNs is considered to be a 'teaching' signal, but in a different context, to the DMS. Mesoaccumbens activation has been strongly linked to Pavlovian learning, the association of an event or situation with the arrival of a salient or aversive stimulus irrespective of instrumental action [149]. Yin et al. [149] postulated that phasic DA activation of MSNs in the NAc (either NAcc, NAcs or both) in response to the conditioned stimulus a predictor of the valence of the unconditioned stimulus ather than the previously discussed reward or aversiveness associated with any particular action [173]. This is a subtle but important distinction suggesting that, unlike the nigrostriatal-DMS function of instrumental learning and action selection, the mesoaccumbens pathway may be acting as an amplifier of actions that have already been selected. This could be described as drive or motivation, instilling and determining the vigour by the which the behaviour is performed [149]. Anatomically, the previously described non-reciprocal feed-forward connections via the midbrain potentially allow this modulation of dorsal striatal structures by its ventral counterpart [141]. This arrangement is the considered mechanism whereby motivational properties are conferred to conditioned stimuli [149]. In addition, research into the highly innate four sequences of grooming in mice gives strong support to the ventral striatum initiating behavioural sequences, in contrast to the dorsal striatum that maintains the sequence or 'syntax' of how the behaviour is performed [174].

3.2.1.5. Habit formation and non-reciprocal loops. The same nonreciprocal feed-forward loops described in the last section, are also considered to be intrinsic to the underlying mechanism behind habit formation [175]. Habit formation normally occurs as a result of an overtraining process and is characterised as a shift from response-outcome ( $\mathrm{R}-\mathrm{O}$ ) to stimulus-response (S-R) learning. During R-O learning, devaluation of the outcome or degradation of the contingency between the response and outcome, will both serve to reduce the level of responding. During the S-R phase, however, responding becomes less affected by either of these manipulations (see [176] for review). Habit formation is characterised by a dorso-lateral shift in cortico-striatal loops where cortical inputs, originally synapsing within DMS MSNs, shift dorsolaterally to MSNs of the DLS [146]. Apart from the implication that non-reciprocal feedforward connections via mid-brain structures are involved in habit formation, the actual process of how this is carried out has yet to be defined. DRD2 MSNs appear to be critical 
to the process [177] potentially by inhibiting their DRD1 counterparts. Similarly, adenosine as a facilitator of LTP within the indirect pathway, is also considered to be important to the habit formation process [178].

Having now outlined basic normal functionality of the basal ganglia, the following section will critically assess what would need to be set in place to shift the normal mechanics towards continual performance of repeated sequences of behaviour (i.e. SB). In the interests of cross-domain integration, we will consider whether such a shift is reflected in neurophysiological evidence underpinning pharmacologically-induced SB.

\subsection{Altered normal basal ganglia function to produce repetitive behavioural sequences}

Given the discussion on the normal working basal ganglia system, how could alterations of this system bring about the manifestation of rigid invariant highly repeated behaviour sequences? At the conceptual level, based on ethological models discussed in Section 2.2, three possible mechanisms of SB development were proposed:

(1) a behavioural sequence predominating within a threshold selection system such that it repeatedly monopolises the action selection process with high motivation maintained through continued presentation of external/internal cues;

(2) a lack of inhibitory feed-back mechanism to prevent the re-queuing of the behaviour sequence. The Hughes and Duncan model [71] identified the lack of inhibitory feedback from non-attainment of the consummatory goal, however, a more fundamental lack of inhibitory feedback at the point of behaviour sequence completion could potentially produce a similar effect;

(3) SB performance is self-reinforcing which would lead to it dominating the action selection process.

For the purposes of this review, only the first two putative mechanisms underpinning SB development will be discussed. As discussed in Section 2.3, there is scant evidence for the selfreinforcement hypothesis, and its inherent unfalsifyability renders it currently unhelpful within models of SB.

In relation to putative mechanism 1, a competing threshold system based on a winner-takes-all strategy chimes strongly with the considered action selection mechanics of the basal ganglia previously discussed [157], although it is considered that current (performing) behavioural sequences always out-compete other putative actions until completion or until termination by an 'emergency' stop signal [164,179]. From the discussion so far, it was considered that normal phasic DA gates putative motor sequences by facilitating and blocking the passage of cortical information through the direct (via DRD1-type MSNs) and indirect (via DRD2-type MSNs) pathways of the dorsal striatum, respectively. In addition, DA activation of the NAc also appears to strengthen overall striatal output in the context of drive and vigour of the selected action. Thus, general up-regulation of the DA system, should, therefore, lead to highly gated, highly motivated behaviours. However, this would potentially apply to all behaviours and would not necessarily explain the predominance of one or two specific motor sequences. A possible explanation for this is that gating strength is determined not by the general level of tonic or phasic DA but rather the level of DA exposure at the time of behavioural sequence performance, i.e. high DA exposure during a specific motor efferent copy results in a highly gated, highly motivated behaviour that predominates over other competing motor sequences. In the context of psychostimulant-induced SB, DA agonist administration is not in the context of any performed motor sequence but it does result in the repeated performance of highly innate pre-programmed motor sequences such as grooming in rodents [180] or others associated with normal repetitive movement performed during early development [181]. Although DA is critical for maintaining the syntax of behavioural sequences, as observed in the four sequential steps of innate grooming in mice [174], and upregulated DAergic transmission into the striatum results in highly repeated performance of that sequence [182], it still does not explain why DA agonist administration results in particular behavioural sequences predominating. Innate behaviours such as grooming and repetitive movement during early development may have an intrinsic lower levels of selection threshold, and it may be this that goes part way towards explaining why they manifest as SB. However, many animal SBs do not fall into this category such as crib-biting in horses, elephants weaving, figure of 8 pacing in large cats and tail chasing in dogs. These behavioural sequences appear to originate and evolve from redirected behaviour performed within restrictive environments where consummatory goals cannot be attained [183]. If, given the discussion so far, low selection threshold is the basis for predominating behavioural sequences, how is this characteristic conferred to these non-innate behavioural patterns? The answer to this may lie within the neurophysiological environment in which these behaviours are initially performed, which is associated with the physiological consequences of stress. Stress has numerous neurophysiological correlates [184-189] but potentially the most relevant is the high and sustained activation of the mescoaccumebns pathway (VTA to ventral striatum) [188,190-193]. Dopamine exposure during repeated behaviour sequence performance associated with non-attainment of goals could theoretically enhance gating at the level of the striatum and thus lower the selection threshold for the behavioural sequence in question.

In relation to putative mechanism 2 , the re-queuing aspect of the behavioural sequences could reflect the lack of the lack of inhibitory feedback from non-attainment of the consummatory goal or a more fundamental lack of inhibitory feedback at the point of behaviour sequence completion. In addition, the highly invariable and behaviourally restrictive nature of the environment in which spontaneous SB is often observed means that internal and external cues are more likely to persist thus perpetually eliciting or re-queuing the same highly invigorated behavioural sequence with negative feedback in place. This raises a critical question about behavioural control generally and the mechanisms that are normally in place to inhibit repeated performance of behavioural sequences. Two possible mechanisms were previously described that could be acting in this functional capacity. Firstly, the STN appears to have executive control in inhibiting basal ganglia and motor output. Indeed, systemic administration of cocaine (DAT blocker) inhibits hyperdirect STN activation of the $\mathrm{SNr}$ interpreted as a disengagement of the 'global brake' system discussed in Section 3.2.3 [194]. Although this brake is predominantly discussed in the context of conflict during action selection, it may also act as a mediator of negative feedback on behaviours recently performed.

The second mechanism by which repetition of behavioural sequences could be terminated, is through behavioural switching, highlighting the previous question of whether behavioural sequences actually require a stop signal or whether they are simply superseded by other higher activation behaviours. Thalamic projections to cholinergic striatal interneurons appear to mediate this switching process and, interestingly, using in vitro and in vivo techniques, systemic administration of DA agonists significantly attenuates striatal levels of acetylcholine, potentially disengaging the switching mechanism and allowing particular motor sequences to predominate in a repetitive fashion [195].

In summary, and in the light of altered basal ganglia mechanics, SB could be the result of (a) highly gated motor sequences 
that already have innate properties of low selection threshold and predominate over other competing actions through overactivation of DAergic systems, (b) highly gated motor sequence as a result of concomitant stress-induced DA release, and/or (c) dysfunction of the inhibitory mechanism at the termination of the behavioural sequence through cortical activation of the STN or, in terms of allowing behavioural sequences to out-compete each other through a process of switching mediated through thalamic innervation of cholinergic interneurons.

\section{Comparing the neurophysiological profile of spontaneous SB}

In the previous section, we described a potential model of SB in which the repetitive unvarying behaviours characteristic of SB are the result either of highly-gated motor sequences predominating the behavioural repertoire, or of disinhibition of the termination of behavioural sequences. In the light of the discussion so far, what do the neurobiological correlates of spontaneous SB animals suggest about altered working mechanics of the basal ganglia and how does this information sit with the envisaged pre-requisites for SB development? In this section, we link the functional characteristics of the basal ganglia to the neurophysiological profile of SB animals.

Presti and Lewis [105] reported high dynorphin/enkephalin ratios in the DLS of high, compared to low, spontaneous SB deer mice. They interpreted this as an imbalance between the direct and indirect pathways and thus enhanced efferent neural transmission from the striatum to cortex. Spontaneous SB performance was also attenuated by striatal infusion of NDMA or DRD1 antagonists, again considered to alter the balance of direct and indirect basal ganglia activity and its ability to suppress overall striatocortical output [89]. Furthermore, Tanimura et al. [100] observed significantly reduced activation of the STN in high SB mice of the same strain that was attenuated by the systemic administration of adenosine agonists. This suggested imbalance of the direct and indirect pathway but more specifically a down-regulation of the indirect pathway such that its normal inhibitory functionality is not operational.

Although this work describes SB development as the simple over expression of behavioural sequences due to a lack of inhibition from the indirect dorsal striatal pathway, it is potentially not supported by recent evidence from pharmacologically-induced SB. For example, electrophysiological measurements from the $\mathrm{SNr}$ during cortical stimulation by Aliane et al. [194] suggested that pharmacologically-induced SB is not caused by a direct/indirect pathway imbalance but rather is due to an imbalance between the medial prefrontal and sensorimotor circuits of the basal ganglia. This work is not completely clear, however, as the study relied on inhibition duration as an inferred measure of direct pathway activity. Measuring thalamic output back to cortical regions would have provided a more confident measure of direct pathway activity in this respect. In addition, the difference in these two sets of studies may reflect critical differences in the underlying neurophysiology between the two types of SB (psychostimulant versus environmentally-induced). This is supported by other data within the same studies that demonstrated (a) DRD2 antagonists attenuate or exacerbate psychostimulant and environmentallyinduced SB, respectively [95,196], and (b) that both DRD1, DRD2 and DRD1/DRD2 combined agonists do not exacerbate spontaneous SB.

As we discussed in Section 2.4, some causal models have suggested that the ventral rather than the dorsal striatum could be critical to SB development. Spontaneous SB that is genotype-dependent has been associated with stress-induced alterations in LTP in the mesoaccumbens DA pathway (VTA-NAc), as indicated by up-regulation of DRD1 and DRD2 in the NAc and concurrent down-regulation of D2 autoreceptors in the VTA [56,101-103]. Similar observations have been made in the horse, where stereotypic (crib-biting) animals had significantly higher DRD1 and DRD2 in the NAc and significantly lower DRD1 in the DMS, as compared to non-stereotypic horses [104]. Thus, evidence tends to suggest that there is also a ventral striatal component of SB development and maintenance. Indeed, when assessing the human repetitive disorder literature, $\mathrm{OCD}$ has been strongly linked to overactivation of the anterior cingulate and orbito-frontal cortices and their projections to the ventral striatum $[20,21,114]$. Furthermore, psychostimulant-induced predominance of striosomes over matrix has been closely correlated with the degree of SB performance (see [130] for review). Functionally this has been interpreted as possible accentuation of the ventral striatum and thus enhanced activation of motivation pathways through the basal ganglia [197]. Given the previous discussion on the general functionality of this region and how it can potentially affect more dorsal striatal structures through non-reciprocal circuitry, these data seem to suggest increased invigoration of selected actions within the SB phenotype. Although this fits with the previously discussed Hughes and Duncan[71] notion that the hyper-motivated phenotype is more likely to remain within appetitve positive feedback loop, one would anticipate a more generalised effect not limited to the SB sequences.

Overall therefore, the evidence suggests that SB is associated with a neurophysiological state within the basal ganglia that creates high gating and high invigoration of selected actions. In addition, it seems that concurrently, the inhibitory mechanism may be lacking in order to allow other behavioural sequence to compete. The specificity of this effect on one behavioural sequence may be caused by: (a) an extreme peak in DA at the time of that behaviour sequence performance (the putative SB) resulting in a permanent high-gating of this behaviour followed by its perpetual over-expression, or (b) by exacerbation of already highly prioritised innate behavioural sequences (e.g. grooming).

\section{Conclusion}

In summary, we have shown that over-activation of the direct, and under-activation of the indirect, pathways of the dorsal striatum may lead to facilitated gating of specific behavioural sequences. It is still not completely clear whether the indirect pathway is functionally responsible for inhibiting an action selected by the direct pathway (i.e. acting as a break) or inhibiting other actions competing with the selected action, or both. This is important since under-activation of the indirect pathway would theoretically enhance the competing power of other behaviour sequences thus preventing one behaviour sequence (SB) from predominating. Further iterative research using BG computational models and electrophysiological studies will hopefully elucidate the exact roles of the direct, indirect and hyperdirect pathways during the action selection process. We have also suggested that over-activation of ventral striatal systems may potential amplify the selection of specific behavioural sequences. In addition, we have provided evidence that under-activation of the STN implicated in spontaneous SB development could relate to a lack of inhibition of behavioural sequences once performed preventing the normal inhibition of re-performance. We extended this to suggest that DAergic inhibition of cholinergic interneurons may interfere with the behavioural switching process.

Two major questions were also prompted from the discussion: (1) How are incumbent behavioural sequences superseded? and, (2) If certain behavioural sequences are always highly gated and highly amplified and without inhibitory control, will they continually and repeatedly win the action selection process? High gating 
and amplification of behavioural sequences does not, however, explain why only certain sequences become SB. This may reflect inbuilt low threshold behavioural sequences associated with development and ethogram of the species or stress-induced DA exposure at the time of behavioural sequences performance where those behaviours have appetitive origins in the context of unobtainable goals.

In Section 3.2, we proposed three mechanisms by which SB could manifest. The third mechanism on the list, that the behavioural sequence results in activation of reward pathways such that the behaviour predominates the action selection process, was beyond the scope of this review. This does not mean that we discount this as a potentially important mechanism but evidence for it is presently less clear. For example, we have seen that SB animals show a propensity for higher S-R (i.e. rather than R-O) learning strategies [88], which would not fit with this model.

Finally, we have presented evidence that links the development of spontaneous SB with dysregulation of the basal ganglia. The causes of this dysregulation appear to be a complex interaction of innate predisposition and environmental insult, in particular involving significant acute or chronic stress. The main goal of researchers in the field of SB is not only to help characterise the factors that lead certain individual animals and species to be predisposed to developing SB, but also to teach us more about learning in general, and normative behavioural control. The model we have presented here is the first to provide this synthesis in the context of integrative, cross-domain analysis of SB. Nonetheless, the functional mechanics of the basal ganglia system is an area of ongoing research and the normal working system presented here will undoubtedly be subjected to revisions at this work develops. This may substantially change the framework upon which the underlying mechanisms of SB development is being critically assessed. The review presented here provides a strong starting point for continued iterative and cross-domain analysis in order to elucidate normal and abnormal behavioural control.

\section{References}

[1] Mason GJ. Stereotypies-a critical review. Anim Behav 1991:41:1015-37.

[2] Cho AK, Melega WP, Kuczenski R, Segal DS, Schmitz DA. Caudate-putamen dopamine and stereotypy response profiles after intravenous and subcutaneous amphetamine. Synapse (New York, NY) 1999;31:125-33.

[3] Inglis WL, Allen LF, Whitelaw RB, Latimer MP, Brace HM, Winn P. An investigation into the role of the pedunculopontine tegmental nucleus in the mediation of locomotion and orofacial stereotypy induced by $d$-amphetamine and apomorphine in the rat. Neuroscience 1994;58:817-33.

[4] Blanchard RJ, Hebert M, Dulloog L, Markham C, Figueira R, Nishimura O, et al. Cocaine-induced sniffing stereotypy changes in response to threat. Pharmacol Biochem Behav 2000;66:249-56.

[5] Canales JJ, Gilmour G, Iversen SD. The role of nigral and thalamic output pathways in the expression of oral stereotypies induced by amphetamine injections into the striatum. Brain Res 2000;856:176-83.

[6] Capper-Loup C, Canales JJ, Kadaba N, Graybiel AM. Concurrent activation of dopamine D-1 and D-2 receptors is required to evoke neural and behavioral phenotypes of cocaine sensitization. J Neurosci 2002;22:6218-27.

[7] Graybiel AM, Moratalla R. Dopamine uptake sites in the striatum are distributed differentially in striosome and matrix compartments. Proc Nat Acad Sci USA 1989;86:9020-4.

[8] Hirabayashi M, Okada S, Tadokoro S. Comparison of sensitization to ambulation-increasing effects of cocaine and methamphetamine after repeated administration in mice. J Pharm Pharmacol 1991;43:827-30.

[9] Bordi F, Meller E. Enhanced behavioral stereotypies elicited by intrastriatal injection of $\mathrm{d} 1$ and $\mathrm{d} 2$ dopamine agonists in intact rats. Brain Res 1989;504:276-83.

[10] Saka E, Goodrich C, Harlan P, Madras BK, Graybiel AM. Repetitive behaviors in monkeys are linked to specific striatal activation patterns. J Neurosci 2004;24:7557-65.

[11] Gale KN, Murray JP, Horita A. Modification of apomorphine induced stereotypies in rates by aversive conditioning. Proc West Pharmacol Soc $1975 ; 18: 375-9$

[12] Presti MF, Powell SB, Lewis MH. Dissociation between spontaneously emitted and apomorphine-induced stereotypy in Peromyscus maniculatus bairdii. Physiol Behav 2002;75:347-53.
[13] Garner JP, Mason GJ. Evidence for a relationship between cage stereotypies and behavioural disinhibition in laboratory rodents. Behav Brain Res 2002;136:83-92.

[14] Fernandez LT, Bashaw MJ, Sartor RL, Bouwens NR, Maki TS. Tongue twisters: feeding enrichment to reduce oral stereotypy in giraffe. Zoo Biol 2008;27:200-12.

[15] Lawrence AB, Terlouw EMC. A review of behavioral-factors involved in the development and continued performance of stereotypic behaviors in pigs. J Anim Sci 1993;71:2815-25.

[16] Zanella AJ, Broom DM, Hunter JC, Mendl MT. Brain opioid receptors in relation to stereotypies, inactivity, and housing in sows. Physiol Behav 1996;59:769-75.

[17] Wiepkema PR, Vanhellemond KK, Roessingh P, Romberg H. Behavior and abomasal damage in individual veal calves. Appl Anim Behav Sci 1987;18:257-68.

[18] Mason G, Rushen J. Stereotypic animal behaviour: fundamentals and applications to welfare. In: Mason G, Rushen J, editors. Stereotypic animal behaviour: fundamentals and applications to welfare. Wallingford, Oxon: CAB International; 2006.

[19] Bourreau Y, Roux S, Gomot M, Barthelemy C. [Repetitive and restricted behaviours (RRB) in autism: clinical evaluation]. L'Encephale 2009;35:340-6.

[20] Modell JG, Mountz JM, Curtis GC, Greden JF. Neurophysiologic dysfunction in basal ganglia/limbic striatal and thalamocortical circuits as a pathogenetic mechanism of obsessive-compulsive disorder. J Neuropsychiatry Clin Neurosci 1989

[21] Graybiel AM, Rauch SL. Toward a neurobiology of obsessive-compulsive disorder. Neuron 2000;28:343-7.

[22] Leckman JF. Tourette's syndrome. Lancet 2002;360:1577-86.

[23] Barnes TR, Rossor M, Trauer T. A comparison of purposeless movements in psychiatric patients treated with antipsychotic drugs, and normal individuals. J Neurol Neurosurg Psychiatry 1983;46:540-6.

[24] Eggers C. [Schizophrenia in childhood and adolescence, symptomatology, clinical course, etiological and therapeutic aspects]. Z Arztl Fortbild Qualitatssich 2002;96:567-77.

[25] Ellison G. Stimulant-induced psychosis, the dopamine theory of schizophrenia, and the habenula. Brain Res Brain Res Rev 1994;19:223-39.

[26] Taylor JR, Morshed SA, Parveen S, Mercadante MT, Scahill L, Peterson BS, et al. An animal model of Tourette's syndrome. Am J Psychiatry 2002;159:657-60.

[27] Harris KM, Mahone EM, Singer HS. Nonautistic motor stereotypies: clinical features and longitudinal follow-up. Pediatr Neurol 2008;38:267-72.

[28] Mahone EM, Bridges D, Prahme C, Singer HS. Repetitive arm and hand movements (complex motor stereotypies) in children. J Pediatr 2004;145:391-5.

[29] Singer HS. Motor stereotypies. Semin Pediatr Neurol 2009;16:77-81.

[30] Wolf DS, Singer HS. Pediatric movement disorders: an update. Curr Opin Neurol 2008;21:491-6.

[31] Langen M, Durston S, Kas MJH, van Engeland H, Staal WG. The neurobiology of repetitive behavior: ... and men. Neurosci Biobehav Rev 2011:35:356-65.

[32] Langen M, Kas MJH, Staal WG, van Engeland H, Durston S. The neurobiology of repetitive behavior: of mice. Neurosci Biobehav Rev 2011;35:345-55.

[33] Mason GJ, Latham NR. Can't stop, won't stop: is stereotypy a reliable animal welfare indicator? Anim Welf 2004;13:S57-69.

[34] Wiepkema PR, Schouten WGP. Stereotypies in sows during chronic stress. Psychother Psychosom 1992;57:194-9.

[35] Young R. Environmental enrichment. Oxford, UK: 2003.

[36] Parker M, Goodwin D, Redhead E, Mitchell H. The effectiveness of environmental enrichment on reducing stereotypic behaviour in two captive vicugna (Vicugna vicugna). Anim Welf 2006;15:59-62.

[37] Mellen JD, Shepherdson DJ, Hutchins M Epilogue. The future of environmental enrichment. In: Zoo and aquarium biology and conservation series. Second nature: environmental enrichment for captive animals; 1998. p. 329-36

[38] Lazarus RS, Folkman S. Stress. New York, NY: Appraisal and Coping; 1984.

[39] Rushen J. The coping hypothesis of stereotypic behavior. Anim Behav 1993;45:613-5

[40] Sambraus HH. Stereotypies. In: Fraser AF, Tribe DE, editors. Ethology of farm animals. Amsterdam: Elsevier; 1996. p. 431-41.

[41] Dantzer R. Behavioral, physiological and functional-aspects of stereotyped behavior-a review and a re-interpretation. J Anim Sci 1986:62:1776-86.

[42] Wiepkema PR, Koolhaas JM. Stress and animal welfare. Anim Welf 1993;2:195-218

[43] Selye S. The evolution of the stress concept. Am Sci 1973;61:692-9.

[44] Rushen J. In: AE Network, editor. Stereotypies. 1995

[45] Dantzer R, Mormede P. Stress in farm-animals-a need for reevaluation. J Anim Sci 1983;57:6-18.

[46] Friend TH. Behavioral-aspects of stress. J Dairy Sci 1991:74:292-303.

[47] Ladewig J, de Passille AMB, Rushen J, Terlouw EMC, von Borell E. Stress and the physiological correlates of stereotypic behaviour. In: Lawrence AB, Rushen J, editors. Stereotypic animal behaviour: fundamentals and applications to welfare. Wallingford, Oxon: CAB International; 1993. p. 97-118.

[48] Mason GJ. Age and context affect the stereotypies of caged mink. Behaviour 1993;127:191-229.

[49] Robbins TW, Mittleman G, OBrien J, Winn P. The neuropsychological significance of stereotypy induced by stimulant drugs. In: Cooper SJ, Dourish CT, editors. Neurobiology of stereotyped behaviour. Oxford, UK: Clarendon Press; 1990. p. 25-63.

[50] Appleby MC, Lawrence AB. Food restriction as a cause of stereotypic behavior in tethered gilts. Anim Prod 1987;45:103-10.

(1) 
[51] Hansen CPB. Stereotypies in ranch mink-the effect of genes, litter size and neighbors. Behav Processes 1993;29:165-78.

[52] Schoenecker B, Heller KE. Indication of a genetic basis of stereotypies in laboratory-bred bank voles (Clethrionomys glareolus). Appl Anim Behav Sci 2000;68:339-47.

[53] Jones M, van Lierop M, Pillay N. All a mother's fault? Transmission of stereotypy in striped mice Rhabdomys. Appl Anim Behav Sci 2008;115:82-9.

[54] Schwaibold U, Pillay N. Stereotypic behaviour is genetically transmitted in the African striped mouse Rhabdomys pumilio. Appl Anim Behav Sci 2001;74:273-80.

[55] Cabib S, Puglisiallegra S. Opposite responses of mesolimbic dopamine system to controllable and uncontrollable aversive experiences. J Neurosci 1994; 14:3333-40.

[56] Cabib S, Giardino L, Calza L, Zanni M, Mele A, Puglisiallegra S. Stress promotes major changes in dopamine receptor densities within the mesoaccumbens and nigrostriatal systems. NeuroScience 1998;84:193-200.

[57] Duncan IJH, Wood-Gush DGM. Thwarting of feeding behaviour in the domestic fowl. Anim Behav 1972;20:444-51.

[58] Aggrey SE, Kroetzl H, Foelsch DW. Behavior of laying hens during induced molting in 3 different production systems. Appl Anim Behav Sci 1990;25:97-105.

[59] Savory CJ, Seawright E, Watson A. Stereotyped behavior in broiler breeders in relation to husbandry and opioid receptor blockade. Appl Anim Behav Sci 1992;32:349-60.

[60] Terlouw EMC, Lawrence AB, Illius AW. Influences of feeding level and physical restriction on development of stereotypies in sows. Anim Behav 1991;42:981-91.

[61] Cooper JJ, Nicol CJ. Stereotypic behavior affects environmental preference in bank voles, Clethrionomys-glareolus. Anim Behav 1991;41:971-7.

[62] Bildsoe M, Heller KE, Jeppesen LL. Effects of immobility stress and food restriction on stereotypies in low and high stereotyping female ranch mink. Behav Processes 1991;25:179-89.

[63] Redbo I, Emanuelson M, Lundberg K. Oredsson N. Feeding level and oral stereotypies in dairy-cows. Anim Sci 1996;62:199-206.

[64] Redbo I, Nordblad A. Stereotypies in heifers are affected by feeding regime. Appl Anim Behav Sci 1997;53:193-202.

[65] Redbo I. Stereotypies and cortisol secretion in heifers subjected to tethering. Appl Anim Behav Sci 1993;38:213-25.

[66] Marsden D, Woodgush DGM. Abnormal-behavior versus production performance criteria in the assessment of welfare in housed lambs. Appl Anim Behav Sci 1986; $15: 90-1$

[67] Hubrecht RC, Serpell JA, Poole TB. Correlates of pen size and housing conditions on the behavior of kenneled dogs. Appl Anim Behav Sci 1992;34:365-83.

[68] Mason G, Bateson M. Motivation and the organisation of behaviour. In: Jensen $P$, editor. The ethology of domestic animals: an introductory text. CAB International; 2009. p. 38-56.

[69] Lorenz K. The comparative method in studying innate behaviour patterns. In: Symposium of the Society for Experimental Biology. 1950.

[70] Von Holst E. The different behavior of central nervous function mechanisms, as seen in animal experiments. Nervenarzt 1953;24:1-10.

[71] Hughes BO, Duncan IJH. The notion of ethological need, models of motivation and animal-welfare. Anim Behav 1988;36:1696-707.

[72] Rushen J. Stereotyped behavior, adjunctive drinking and the feeding periods of tethered sows. Anim Behav 1984;32:1059-67.

[73] Bodfish JW, Symons FJ, Parker DE, Lewis MH. Varieties of repetitive behavior in autism: comparisons to mental retardation. J Autism Dev Disord 2000;30:237-43.

[74] Goldman S, Wang C, Salgado MW, Greene PE, Kim M, Rapin I. Motor stereotypies in children with autism and other developmental disorders. Dev Med Child Neurol 2009;51:30-8.

[75] Koegel RL, Covert A. The relationship of self-stimulation to learning in autistic children1. J Appl Behav Anal 1972;5:381-7.

[76] Lovaas I, Newsom C, Hickman C. Self-stimulatory behavior and perceptual reinforcement. J Appl Behav Anal 1987;20:45-68.

[77] Cunningham AB, Schreibman L. Stereotypy in autism: the importance of function. Res Autism Spectr Disord 2008;2:469-79.

[78] Mason G, Rushen J. Stereoypic animal behaviour: fundamentals and applications to welfare. second ed. CABI; 2006.

[79] Lucey J, Costa D, Adshead G, Deahl M, Busatto G, Gacinovic S, et al. Brain blood flow in anxiety disorders, OCD, panic disorder with agoraphobia, and post-traumatic stress disorder on 99mTcHMPAO single photon emission tomography (SPET). Br J Psychiatry 1997;171:346-50.

[80] Lin H, Katsovich L, Ghebremichael M, Findley DB, Grantz H, Lombroso PJ, et al. Psychosocial stress predicts future symptom severities in children and adolescents with Tourette syndrome and/or obsessive-compulsive disorder. J Child Psychol Psychiatry 2007;48:157-66.

81] Motlagh MG, Katsovich L, Thompson N, Lin H, Kim Y-S, Scahill L, et al Severe psychosocial stress and heavy cigarette smoking during pregnancy: an examination of the pre-and perinatal risk factors associated with ADHD and Tourette syndrome. Eur Child Adolesc Psychiatry 2010;19:755-64.

[82] Lombroso PJ, Mack G, Scahill L, King RA, Leckman J. Exacerbation of Gilles de la Tourette's syndrome associated with thermal stress: a family study. Neurology 1991;41:1984-

[83] Silva RR, Munoz DM, Barickman J, Friedhoff AJ. Environmental factors and related fluctuation of symptoms in children and adolescents with Tourette's disorder. J Child Psychol Psychiatry 1995;36:305-12.
[84] Chappell P, Riddle M, Anderson G, Scahill L, Hardin M, Walker D, et al. Enhanced stress responsivity of Tourette syndrome patients undergoing lumbar puncture. Biol Psychiatry 1994;36:35-43.

[85] Liebowitz MR, Turner SM, Piacentini J, Beidel DC, Clarvit SR, Davies SO, et al. Fluoxetine in children and adolescents with OCD: a placebo-controlled trial. J Am Acad Child Adolesc Psychiatry 2002;41:1431-8.

[86] Randrup AA, Munkvad I, Udsen P. Adrenergic mechanisms and amphetamine induced abnormal behaviour. Acta Pharmacol Toxicol 1997;20:145-57.

[87] Cooper SJ, Dourish CJ. An introduction to the concept of stereotypy and historical perspective on the role of brain dopamine. In: Cooper SJ, Dourish CT, editors. Neurobiology of stereotyped behaviour. Oxford, UK: Clarendon Press; 1990. p. 1-24.

[88] Ishiguro A, Inagaki M, Kaga M. Stereotypic circling behavior in mice with vestibular dysfunction: asymmetrical effects of intrastriatal microinjection of a dopamine agonist. Int J Neurosci 2007;117:1049-64.

[89] Presti MF, Mikes HM, Lewis MH. Selective blockade of spontaneous motor stereotypy via intrastriatal pharmacological manipulation. Pharmacol Biochem Behav 2003;74:833-9.

[90] Kelly PH, Seviour PW, Iversen SD. Amphetamine and apomorphine responses in rat following 6-OHDA lesions of nucleus accumbens septi and corpus striatum. Brain Res 1975;94:507-22.

[91] Kennes D, Odberg FO, Bouquet Y, De Rycke PH. Changes in naloxone and haloperidol effects during the development of captivity-induced jumping stereotypy in bank voles. Eur J Pharmacol 1988;153:19-24.

[92] Kostal L, Savory CJ. Influence of pharmacological manipulation of dopamine and opioid receptor subtypes on stereotyped behavior of restricted-fed fowls. Pharmacol Biochem Behav 1994;48:241-52.

[93] von Borell E, Hurnik JF. The effect of haloperidol on the performance of stereotyped behavior in sows. Life Sci 1991;49:309-14.

[94] Willemse T, Mudde M, Josephy M, Spruijt BM. The effect of haloperidol and naloxone on excessive grooming behavior of cats. Eur Neuropsychopharmacol 1994;4:39-45.

[95] Presti MF, Gibney BC, Lewis MH. Effects of intrastriatal administration of selective DAergic ligands on spontaneous stereotypy in mice. Physiol Behav 2004;80:433-9.

[96] Dodman NH, Shuster L, Court MH, Dixon R. Investigation into the use of narcotic-antagonists in the treatment of a stereotypic behavior pattern (cribbiting) in the horse. Am J Vet Res 1987;48:311-9.

[97] McBride SD, Cuddeford D. The putative welfare-reducing effects of preventing equine stereotypic behaviour. Anim Welf 2001;10:173-89.

[98] Schouten W, Rushen J. Effects of naloxone on stereotypic and normal behavio of tethered and loose-housed sows. Appl Anim Behav Sci 1992;33:17-26.

[99] Graybiel AM. Neurotransmitters and neuromodulators in the basal ganglia. Trends Neurosci 1990;13:244-54.

[100] Tanimura Y, Vaziri S, Lewis MH. Indirect basal ganglia pathway mediation of repetitive behavior: attenuation by adenosine receptor agonists. Behav Brain Res 2010;210:116-22

[101] Cabib S, Puglisiallegra S, Oliverio A. Chronic stress enhances apomorphineinduced stereotyped behavior in mice-involvement of endogenous opioids. Brain Res 1984:298:138-40.

[102] Cabib S, Bonaventura N. Parallel strain-dependent susceptibility to environmentally-induced stereotypies and stress-induced behavioral sensitization in mice. Physiol Behav 1997;61:499-506.

[103] Cabib S, Ventura R, Puglisi-Allegra S. Opposite imbalances between mesocortical and mesoaccumbens dopamine responses to stress by the same genotype depending on living conditions. Behav Brain Res 2002;129:179-85.

[104] McBride SD, Hemmings A. Altered mesoaccumbens and nigro-striata dopamine physiology is associated with stereotypy development in a nonrodent species. Behav Brain Res 2005;159:113-8.

[105] Presti MF, Lewis MH. Striatal opioid peptide content in an animal model of spontaneous stereotypic behavior. Behav Brain Res 2005;157:363-8.

[106] Hemmings A, McBride SD, Hale CE. Perseverative responding and the aetiol ogy of equine oral stereotypy. Appl Anim Behav Sci 2007;104:143-50.

[107] Vickery SS, Mason GJ. Stereotypy and perseverative responding in caged bears: further data and analyses. Appl Anim Behav Sci 2005;91:247-60.

[108] Dallaire JA, Meagher RK, Diez-Leon M, Garner JP, Mason GJ. Recurrent perseveration correlates with abnormal repetitive locomotion in adult mink but is not reduced by environmental enrichment. Behav Brain Res $2011 ; 224: 213-22$

[109] Pomerantz O, Paukner A, Terkel J. Some stereotypic behaviors in rhe sus macaques (Macaca mulatta) are correlated with both perseveration and the ability to cope with acute stressors. Behav Brain Res 2012;230: 274-80.

[110] Gross AN, Engel AKJ, Richter SH, Garner JP, Wuerbel H. Cage-induced stereotypies in female ICR CD-1 mice do not correlate with recurrent perseveration. Behav Brain Res 2011;216:613-20.

[111] Parker M, Redhead ES, Goodwin D, McBride SD. Impaired instrumental choice in crib-biting horses (Equus caballus). Behav Brain Res 2008:191:137-40.

[112] Parker M, McBride SD, Redhead ES, Goodwin D. Differential place and response learning in horses displaying an oral stereotypy. Behav Brain Res 2009;200:100-5.

[113] Tanimura Y, Yang MC, Lewis MH. Procedural learning and cognitive flexibility in a mouse model of restricted, repetitive behaviour. Behav Brain Res 2008;189:250-6.

[114] Saxena S, Brody AL, Schwartz JM, Baxter LR. Neuroimaging and frontalsubcortical circuitry in obsessive-compulsive disorder. Br J Psychiatry 1998 
[115] Worbe Y, Gerardin E, Hartmann A, Valabrégue R, Chupin M, Tremblay L, et al. Distinct structural changes underpin clinical phenotypes in patients with Gilles de la Tourette syndrome. Brain 2010;133:3649-60.

[116] Everitt BJ, Robbins TW. Neural systems of reinforcement for drug addiction: from actions to habits to compulsion. Nat Neurosci 2005;8:1481-9.

[117] Voorn P, Vanderschuren LJ, Groenewegen HJ, Robbins TW, Pennartz CM. Putting a spin on the dorsal-ventral divide of the striatum. Trends Neurosci 2004:27:468-74.

[118] Haber SN. Neural circuits of reward and decision making: integrative networks across corticobasal ganglia loops. In: Neural basis of motivational and cognitive control; 2011. p. 21-35.

[119] Wall NR, De La Parra M, Callaway EM, Kreitzer AC. Differential innervation of direct- and indirect-pathway striatal projection neurons. Neuron 2013;79:347-60.

[120] Choi EY, Yeo BTT, Buckner RL. The organization of the human striatum estimated by intrinsic functional connectivity. J Neurophysiol 2012;108:2242-63.

[121] Mink JW. The basal ganglia: focused selection and inhibition of competing motor programs. Prog Neurobiol 1996;50:381-425.

[122] Wickens JR, Arbuthnott GW. Chapter 19-gating of cortical input to the striatum. In: Heinz Steiner, Kuei YT, editors. Handbook of behavioral neuroscience. Amsterdam: Elsevier; 2010. p. 341-51.

123] Maurice N, Deniau JM, Glowinski J, Thierry AM. Relationships between the prefrontal cortex and the basal ganglia in the rat: physiology of the corticonigral circuits. J Neurosci 1999; 19:4674-81.

124] Gerfen CR, Bolam JP. Chapter 1-the neuroanatomical organization of the basal ganglia. In: Heinz Steiner, Kuei YT, editors. Handbook of behavioral neuroscience. Amsterdam: Elsevier; 2010. p. 3-28.

[125] Haynes WIA, Haber SN. The organization of prefrontal-subthalamic inputs in primates provides an anatomical substrate for both functional specificity and integration: implications for basal ganglia models and deep brain stimulation. J Neurosci 2013;33:4804-14.

126] Haynes KA, Leibovitch BA, Rangwala SH, Craig C, Elgin SC. Analyzing heterochromatin formation using chromosome 4 of Drosophila melanogaster. Cold Spring Harb Symp Quant Biol 2004;69:267-72.

[127] Charpier S, Beurrier C, Paz JT. Chapter 15-the subthalamic nucleus: from in vitro to in vivo mechanisms. In: Heinz Steiner, Kuei YT, editors. Handbook of behavioral neuroscience. Amsterdam: Elsevier; 2010. p. 259-73.

[128] Nakanishi H, Kita H, Kitai ST. An N-methyl-D-aspartate receptor mediated excitatory postsynaptic potential evoked in subthalamic neurons in an invitro slice preparation of the rat. Neurosci Lett 1988;95:130-6.

[129] Magill PJ, Sharott A, Bevan MD, Brown P, Bolam JP. Synchronous unit activity and local field potentials evoked in the subthalamic nucleus by cortical stimulation. J Neurophysiol 2004;92:700-14.

[130] Crittenden JR, Graybiel AM. Basal ganglia disorders associated with imbalances in the striatal striosome and matrix compartments. Front Neuroanat 2011:5.

[131] Graybiel AM. Neurochemically specified subsystems in the basal ganglia. Ciba Found Symp 1984;107:114-49.

[132] Nastuk MA, Graybiel AM. Patterns of muscarinic cholinergic binding in the striatum and their relation to dopamine islands and striosomes. J Comp Neurol 1985;237:176-94.

[133] Suzuki T, Miura M, Nishimura K, Aosaki T. Dopamine-dependent synaptic plasticity in the striatal cholinergic interneurons. J Neurosci 2001;21:6492-501.

[134] Canales JJ, Graybiel AM. A measure of striatal function predicts motor stereotypy. Nat Neurosci 2000;3:377-83.

[135] White NM, Hiroi N. Preferential localization of self-stimulation sites in striosomes/patches in the rat striatum. Proc Nat Acad Sci USA 1998:95:6486-91.

[136] Gerfen CR. The neostriatal mosaic-compartmentalization of corticostriatal input and striatonigral output systems. Nature 1984;311:461-4.

137] Di Filippo M, Picconi B, Tantucci M, Ghiglieri V, Bagetta V, Sgobio C, et al. Short-term and long-term plasticity at corticostriatal synapses: implications for learning and memory. Behav Brain Res 2009;199:108-18.

[138] Gerdeman GL, Partridge JG, Lupica CR, Lovinger DM. It could be habit forming: drugs of abuse and striatal synaptic plasticity. Trends Neurosci 2003;26:184-92.

139] Kreitzer AC. Physiology and pharmacology of striatal neurons. Annu Rev Neurosci 2009;32:127-47.

[140] Kalivas PW, Burgess SK, Nemeroff CB, Prange Jr AJ. Behavioral and neurochemical effects of neurotensin microinjection into the ventral tegmental area of the rat. Neuroscience 1983;8:495-505.

[141] Haber SN, Fudge JL, McFarland NR. Striatonigrostriatal pathways in primates form an ascending spiral from the shell to the dorsolateral striatum. J Neurosci 2000;20:2369-82.

[142] Miura M, Masuda M, Aosaki T. Roles of mu-opioid receptors in GABAergic synaptic transmission in the striosome and matrix compartments of the striatum. Mol Neurobiol 2008;37:104-15.

[143] Ding JB, Guzman JN, Peterson JD, Goldberg JA, Surmeier DJ. Thalamic gating of corticostriatal signaling by cholinergic interneurons. Neuron 2010;67:294-307.

[144] Balleine BW, Lijeholm M, Ostlund SB. The integrative function of the basal ganglia in instrumental conditioning. Behav Brain Res 2009;199:43-52.

[145] Redgrave P, Prescott TJ, Gurney K. The basal ganglia: a vertebrate solution to the selection problem? Neuroscience 1999;89:1009-23.
[146] Yin HH, Knowlton BJ. The role of the basal ganglia in habit formation. Nat Rev Neurosci 2006;7:464-76.

[147] Ikemoto S, Panksepp J. The role of nucleus accumbens dopamine in motivated behavior: a unifying interpretation with special reference to reward-seeking. Brain Res Rev 1999;31:6-41.

[148] Cepeda C, Bamford NS, André VM, Levine MS. Chapter 35-alterations in corticostriatal synaptic function in Huntington's and Parkinson's diseases. In: Heinz Steiner, Kuei YT, editors. Handbook of behavioral neuroscience. Amsterdam: Elsevier; 2010. p. 607-23.

[149] Yin HH, Ostlund SB, Balleine BW. Reward-guided learning beyond dopamine in the nucleus accumbens: the integrative functions of cortico-basal ganglia networks. Eur J Neurosci 2008;28:1437-48.

[150] Calabresi P, Picconi B, Tozzi A, Di Filippo M. Dopamine-mediated regulation of corticostriatal synaptic plasticity. Trends Neurosci 2007;30: 211-9.

[151] Redgrave P, Gurney K, Reynolds J. What is reinforced by phasic dopamine signals? Brain Res Rev 2008;58:322-39.

[152] Levesque M, Charara A, Gagnon S, Parent A, Deschenes M. Corticostriatal projections from layer $\mathrm{V}$ cells in rat are collaterals of long-range corticofugal axons. Brain Res 1996;709:311-5.

[153] Lei WL, Jiao Y, Del Mar N, Reiner A. Evidence for differential cortical input to direct pathway versus indirect pathway striatal projection neurons in rats. J Neurosci 2004;24:8289-99.

[154] Lovinger DM. Neurotransmitter roles in synaptic modulation, plasticity and learning in the dorsal striatum. Neuropharmacology 2010;58:951-61.

[155] Surmeier DJ, Ding J, Day M, Wang ZF, Shen WX. D1 and D2 dopamine-receptor modulation of striatal glutamatergic signaling in striatal medium spiny neurons. Trends Neurosci 2007:30:228-35.

[156] Shen WX, Flajolet M, Greengard P, Surmeier DJ. Dichotomous DAergic control of striatal synaptic plasticity. Science 2008;321:848-51.

[157] Gurney K, Prescott TJ, Redgrave P. A computational model of action selection in the basal ganglia: I. A new functional anatomy. Biol Cybern 2001;84:401-10

[158] Frank MJ. Hold your horses: a dynamic computational role for the subthalamic nucleus in decision making. Neural Netw 2006;19:1120-36.

[159] Aron AR, Poldrack RA. Cortical and subcortical contributions to stop signal response inhibition: role of the subthalamic nucleus. J Neurosci 2006;26:2424-33.

[160] Keefe KA, Gerfen CR. D1-D2 dopamine-receptor synergy in striatum-effects of intrastriatal infusions of dopamine agonists and antagonists on immediateearly gene-expression. Neuroscience 1995;66:903-13.

[161] Gong W, Neill DB, Lynn M, Justice JB. Dopamine D-1/D-2 agonists injected into nucleus accumbens and ventral pallidum differentially affect locomotor activity depending on site. Neuroscience 1999;93:1349-58.

[162] Jin X, Tecuapetla F, Costa RM. Basal ganglia subcircuits distinctively encode the parsing and concatenation of action sequences. Nat Neurosci 2014:17.

[163] Freeze BS, Kravitz AV, Hammack N, Berke JD, Kreitzer AC. Control of basal ganglia output by direct and indirect pathway projection neurons. J Neurosci 2013:33:18531-9.

[164] Cavanagh JF, Frank MJ. Stop! Stay tuned for more information. Exp Neurol 2013;247:289-91.

[165] Chambers CD, Garavan H, Bellgrove MA. Insights into the neural basis of response inhibition from cognitive and clinical neuroscience. Neurosci Biobehav Rev 2009;33:631-46.

[166] Schmidt R, Leventhal DK, Mallet N, Chen F, Berke JD. Canceling actions involves a race between basal ganglia pathways. Nat Neurosci 2013;16, 1118U194.

[167] Baunez C, Nieoullon A, Amalric M. In a rat model of parkinsonism, lesions of the subthalamic nucleus reverse increases of reaction-time but induce a dramatic premature responding deficit. J Neurosci 1995;15:6531-41.

[168] Eagle DM, Baunez C. Is there an inhibitory-response-control system in the rat? Evidence from anatomical and pharmacological studies of behavioral inhibition. Neurosci Biobehav Rev 2010;34:50-72.

[169] Eagle DM, Baunez C, Hutcheson DM, Lehmann O, Shah AP, Robbins TW. Stop-signal reaction-time task performance: role of prefrontal cortex and subthalamic nucleus. Cereb Cortex 2008;18:178-88.

[170] Alegre M, Lopez-Azcarate J, Obeso I, Wilkinson L, Rodriguez-Oroz MC, Valencia $\mathrm{M}$, et al. The subthalamic nucleus is involved in successful inhibition in the stop-signal task: a local field potential study in Parkinson's disease. Exp Neurol 2013;239:1-12.

[171] Jin X, Costa RM. Start/stop signals emerge in nigrostriatal circuits during sequence learning. Nature 2010;466:457-62.

[172] Schultz W. Dopamine neurons and their role in reward mechanisms. Curr Opin Neurobiol 1997;7:191-7.

[173] Morris G, Nevet A, Arkadir D, Vaadia E, Bergman H. Midbrain dopamine neurons encode decisions for future action. Nat Neurosci 2006;9:1057-63.

[174] Aldridge JW, Berridge KC. Coding of serial order by neostriatal neurons: a "Natural action" approach to movement sequence. J Neurosci 1998;18:2777-87.

[175] Haber SN, Calzavara R. The cortico-basal ganglia integrative network: the role of the thalamus. Brain Res Bull 2009;78:69-74.

[176] Yin HH, Adermark L, Lovinger DM. Neurotensin reduces glutamatergic transmission in the dorsolateral striatum via retrograde endocannabinoid signaling. Neuropharmacology 2008;54:79-86.

[177] Taverna S, Ilijic E, Surmeier DJ. Recurrent collateral connections of striatal medium spiny neurons are disrupted in models of Parkinson's disease. J Neurosci 2008;28:5504-12. 
[178] Yu CX, Gupta J, Chen JF, Yin HH. Genetic deletion of $A(2 A)$ adenosine receptors in the striatum selectively impairs habit formation. J Neurosci 2009;29:15100-3.

[179] Frank MJ, Samanta J, Moustafa AA, Sherman SJ. Hold your horses: impulsivity, deep brain stimulation, and medication in parkinsonism. Science 2007;318:1309-12.

[180] Berridge KC, Aldridge JW, Houchard KR, Zhuang XX. Sequential superstereotypy of an instinctive fixed action pattern in hyper-DAergic mutant mice: a model of obsessive compulsive disorder and Tourette's. BMC Biol 2005;3.

[181] Thelen E. Rhythmical stereotypies in normal human infants. Anim Behav 1979;27:699-715.

[182] Taylor JL, Rajbhandari AK, Berridge KC, Aldridge JW. Dopamine receptor modulation of repetitive grooming actions in the rat: potential relevance for Tourette syndrome. Brain Res 2010;1322:92-101.

[183] Rushen J, Mason G. A decade-or-more's progress in understanding stereotypic behaviour. In: Mason G, Rushen J, editors. Stereotypic behaviour: fundamentals and implications for welfare. Wallingford, Oxon,UK: CABI; 2006. p. 1-18.

[184] Koob GF. A role for brain stress systems in addiction. Neuron 2008;59:11-34.

[185] Lupien SJ, McEwen BS, Gunnar MR, Heim C. Effects of stress throughout the lifespan on the brain, behaviour and cognition. Nat Rev Neurosci 2009; 10:434-45.

[186] Shin LM, Liberzon I. The neurocircuitry of fear, stress, and anxiety disorders. Neuropsychopharmacology 2010;35:169-91.

[187] Roozendaal B, McEwen BS, Chattarji S. Stress, memory and the amygdala. Nat Rev Neurosci 2009;10:423-33.

[188] Cabib S, Puglisi-Allegra S. The mesoaccumbens dopamine in coping with stress. Neurosci Biobehav Rev 2012;36:79-89.

[189] Dias-Ferreira E, Sousa JC, Melo I, Morgado P, Mesquita AR, Cerqueira JJ, et al. Chronic stress causes frontostriatal reorganization and affects decisionmaking. Science 2009;325:621-5.
[190] Abercrombie ED, Keefe KA, Difrischia DS, Zigmond MJ. Differential effect of stress on invivo dopamine release in striatum, nucleus accumbens, and medial frontal-cortex. J Neurochem 1989;52:1655-8.

[191] Pruessner JC, Champagne F, Meaney MJ, Dagher A. Dopamine release in response to a psychological stress in humans and its relationship to early life maternal care: a positron emission tomography study using (11)C raclopride. J Neurosci 2004;24:2825-31.

[192] Kalivas PW, Duffy P. Selective activation of dopamine transmission in the shell of the nucleus accumbens by stress. Brain Res 1995;675:325-8.

[193] Puglisi-allegra S, Imperato A, Angelucci L, Cabib S. Acute stress induces time-dependent responses in dopamine mesolimbic system. Brain Res 1991;554:217-22.

[194] Aliane V, Perez S, Nieoullon A, Deniau J-M, Kemel M-L. Cocaine-induced stereotypy is linked to an imbalance between the medial prefrontal and sensorimotor circuits of the basal ganglia. Eur J Neurosci 2009;30: 1269-79.

[195] Aliane V, Perez S, Bohren Y, Deniau JM, Kemel ML. Key role of striatal cholinergic interneurons in processes leading to arrest of motor stereotypies. Brain 2011;134:110-8.

[196] Aliane V, Perez S, Deniau JM, Kemel ML. Raclopride or high-frequency stimulation of the subthalamic nucleus stops cocaine-induced motor stereotypy and restores related alterations in prefrontal basal ganglia circuits. Eur J Neurosci 2012;36:3235-45.

[197] Graybiel AM, Canales JJ, Capper-Loup C. Levodopa-induced dyskinesias and dopamine-dependent stereotypies: a new hypothesis. Trends Neurosci 2000;23:S71-7.

[198] Tanimura Y, King MA, Williams DK, Lewis MH. Development of repetitive behavior in a mouse model: roles of indirect and striosomal basal ganglia pathways. Int J Dev Neurosci 2011;29:461-7. 